\title{
Analysis of Methane Hazard Conditions in Mine Headings
}

\author{
Jarosław BRODNY, Magdalena TUTAK
}

\begin{abstract}
One of the most dangerous and the most common hazards in coal mines is methane hazard. This threat is associated with inflammation and/or explosion of methane in the mixture of air. Analysis of the scale of methane hazard allows the selection of such a longwall ventilation system operating, which provides the requisite provisions of the chemical composition of the mine atmosphere, and the required efficiency of methane drainage. The article presents the results of numerical analysis of the flow of the mixture stream of air and methane by the layout of workings of one of the mines. The aim of this study was to analyse the workings and the designation of zones of the ventilation system in question, where there may be dangerous, explosive concentrations of methane. The results are important when taking preventive actions aimed at reducing methane emissions to the external environment in the process of methane drainage.
\end{abstract}

Keywords: ANSYS Fluent; coal mine; methane hazard; numerical research

\section{INTRODUCTION}

Hard coal, which is one of the fundamental energetic raw materials, is mined by underground and open pit methods. Currently, about $60 \%$ of the world coal output is obtained as a result of its underground exploitation [6, $16]$, which due to many hazards is very dangerous.

One of the most common and most dangerous hazards presented in hard coal mine is methane hazard connected with the possibility of inflammation and/or explosion of methane when mixed with air.

Activation of methane hazard in underground mining excavations has negative impact both on working environment of operating crew and on natural environment, through emission of methane to the atmosphere and harmful and poisonous gases created during its combustion reaction:

$$
\begin{aligned}
& \mathrm{CH}_{4}+2 \mathrm{O}_{2} \rightarrow \mathrm{CO}+2 \mathrm{H}_{2} \mathrm{O} \\
& \mathrm{CH}_{4}+2 \mathrm{O}_{2} \rightarrow \mathrm{CO}_{2}+2 \mathrm{H}_{2} \mathrm{O} \\
& \mathrm{CH}_{4}+\mathrm{H}_{2} \mathrm{O} \rightarrow \mathrm{CO}+3 \mathrm{H}_{2}, \\
& 2 \mathrm{H}_{2}+\mathrm{O}_{2} \rightarrow 2 \mathrm{H}_{2} \mathrm{O} \\
& \mathrm{CO}+\mathrm{H}_{2} \mathrm{O} \rightarrow \mathrm{CO}_{2}+\mathrm{H}_{2} .
\end{aligned}
$$

The biggest national deposits of hard coal, exploited in the Upper Silesian Coal Basin, belong to high-methane deposits, of which seams in the most of mines have been classified to III and IV methane hazard category [3], which means that from one ton of mined coal there is emitted at least $4.5 \mathrm{~m}^{3}$ of methane.

For example, in 2014 to the atmosphere (natural environment) together with spent mining air there was emitted $471.17 \mathrm{mln}^{3}$ of methane [8]. Because methane belongs to the group of greenhouse gases, its emission to the atmosphere in such amounts is disadvantageous process.

However, before methane emitted from the exploited excavations comes out to the atmosphere, it is very dangerous for underground working environment. Particularly dangerous is underground explosion of methane, which is a serious menace to the crew and the entire mine.

According to the Act [4], it is assumed that the explosion of methane is a serious breakdown, defined as an event particularly causing emission, fire or explosion resulting from industrial process, in which there is one or more hazardous substances, leading immediately to creation of hazard for human life or health or for the environment, or formation of such hazard with delay.

In the last few years in global mining industry, there have been many explosions and inflammations of methane, in which many thousands of miners were subjected to accidents. Also in Polish hard coal mining in the years 2005-2014, there were registered 28 hazardous events associated with inflammation and explosions of methane. In these events 59 persons died, and 110 were injured [3].

It can be assumed that methane poses a very serious hazard both for underground operating environment and natural environment.

As in the years to come the international and national power industry in considerable degree will be based on coal, it forces actions in order to limit methane hazard in underground working environment and decrease its emission to atmosphere.

Limitation of methane hazard in underground mining excavations is done primarily by preventing the accumulation of dangerous amounts of methane causing its explosive concentrations. Therefore, a proper amount of fresh air is supplied to the excavation, so that the methane concentration will not exceed the allowed value [5]. Simultaneously, stream of fresh air should have proper physical properties (velocity, moisture, temperature) and chemical composition. These parameters should be chosen so that the atmosphere formed in the excavation assures demanded parameters necessary for exploitation works.

Therefore it becomes reasonable to carry out research in order to determine parameters of flowing air stream through underground excavations considering methane emitted from body of coal and rockfall goaves. Such research can be carried out in real underground conditions or with use of modern simulation methods. Carrying out the tests in underground conditions in continuous way is very expensive, dangerous and can be difficult due to exploitation. Particularly, it relates to rockfall goaves, where very often comes to accumulation of dangerous amounts of methane.

It becomes necessary to search such research works, which will in safe way enable to determine parameters of air stream both in mining longwall and goaves. To such 
methods one can include simulation numerical tests [1015], which are presently widely used as research tools for performing the multivariant analyses of the series of processes, including the aerological ones.

In the recent years, to analyze the ventilation problems connected with composition of mining atmosphere as a part of operation environment, the numerical methods are widely used [10, 11, 13, 14]. However, not many researches include three-dimensional analysis considering methane emitted from goaves and mining excavation.

In this paper results of such analysis using numerical fluid mechanics in ANSYS Fluent software are presented. This program gives a lot of opportunities in a range of determination of physical and chemical parameters of air stream and methane mixture in any point of investigated excavation.

Determination of these parameters in such a wide range based on research in the real conditions is practically impossible. However, partial measurements in the underground conditions are necessary for development of flow model and establishment of boundary conditions and verification of the results.

Analyses were performed for real system of excavations in one of domestic mines with a high methane hazard, with use of available measurement results of the selected parameters of ventilating airflow.

The main aim of the research was analysis of the ventilation system of considered excavations and determination of zones, where dangerous explosive methane concentration can occur. Designation of such zones is necessary to ensure the safety of the operating environment for mining crews. Obtained results are also very important in activities in order to limit the methane emissions to external environment in the process of methane drainage.

\section{THE MATHEMATICAL MODEL OF THE FLOW}

Numerical fluid mechanics (CFD) is a method of simulations of phenomena related to flow of liquids and gases, heat and mass transfer, as well as chemical reactions [9].

In the paper this method was used to determine the physical and chemical parameters of the mixture of air and methane, flowing through the real system of mine excavations.

A turbulent flow of viscous incompressible fluid (in this case a gas), was described by the Navier-Stokes system of equations, which together with continuity equation makes a complete system of relationships, allowing to determine pressure and field of flow velocity [9].

Issues connected with transport of fluid are solved based on the following fluid mechanics equations [1]:

\section{The continuity equation}

$\frac{\partial \rho}{\partial t}+\frac{\partial(\rho u)}{\partial x}+\frac{\partial(\rho v)}{\partial y}+\frac{\partial(\rho w)}{\partial z}=0$,

where: $u, v, w$ - directions velocity $(\mathrm{m} / \mathrm{s}), \rho-$ density $\left(\mathrm{kg} / \mathrm{m}^{3}\right)$ and $t$ - time $(\mathrm{s})$.
The momentum equation

$\frac{\partial}{\partial t}(\rho v)+\nabla \cdot(v v)=-\nabla p+\nabla \tau+\rho g+F$

where: $p$ - static pressure $(\mathrm{Pa}), \tau$ - the stress tensor $(\mathrm{Pa})$, $g$ - the gravitational body force $\left(\mathrm{m} / \mathrm{s}^{2}\right)$ and $F-$ the external body force $(\mathrm{N})$.

The basis of the mathematical description of the transport process of the methane emission to the headings is a mass conservation principle related to this gas. Mathematical model of the transport, being a system of equations of advection-diffusion takes the following form [1] for the i-th substance:

The species transport equation

$\frac{\partial}{\partial t}\left(\rho Y_{i}\right)+\nabla \cdot\left(\rho v Y_{i}\right)=-\nabla \cdot J_{i}+R_{i}+S_{i}$

where: $v$ - velocity $(\mathrm{m} / \mathrm{s}), Y_{i}$ - the local mass fraction of each species, $J_{i}$ - the diffusion flux of species $i$ $\left(\mathrm{kg} /\left(\mathrm{m}^{2} \mathrm{~s}\right)\right), R_{i}$ - the net rate of production of species $i$ by chemical reaction, $S_{i}-$ the rate of creation by addition from the dispersed phase plus any user-defined sources.

The mass duffusion in turbulent flows - Fick's law

$J_{i}=-\left(\rho D_{i, m}+\frac{\mu_{t}}{S c_{t}}\right) \nabla Y_{i}$

where: $D_{i, m}$ - the mass diffusion coefficient for species $i$ in the mixture $\left(\mathrm{m}^{2} / \mathrm{s}\right), \mu$ - the viscosity $(\mathrm{Pa} \cdot \mathrm{s}), S_{c t}-$ the turbulent Schmidt number (0.7).

Presented mathematical model of the flow connects description of air flow and transport of gases.

Flow of gas streams through the excavations has turbulent character, that is, the one in which irregular movement of air particles occurs, and its flow parameters undergo unpredictable random changes in space and time $[1,2]$.

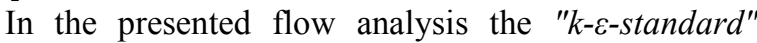
turbulence model was applied. This model describes components of the Reynolds turbulent stress tensors according to the Boussinesq hypothesis. In the formula for the components of stress tensor there occur $k$ and $\varepsilon$ quantities. These quantities require additional two transport equations for single phase flows in the form [1]:

\section{$k$-transport equation}

$\rho \frac{\partial k}{\partial t}+\frac{\partial}{\partial x_{i}}\left(\partial k u_{i}\right)=$

$\frac{\partial}{\partial x_{j}}\left[\left(\mu+\frac{\mu_{t}}{\sigma_{k}}\right) \frac{\partial k}{\partial x_{j}}\right]+G_{k}+G_{b}-\rho \varepsilon-Y_{M}+S_{k}$, 


$$
\begin{aligned}
& \rho \frac{\partial \varepsilon}{\partial t}+\frac{\partial}{\partial x_{i}}\left(\rho \varepsilon u_{i}\right)=\frac{\partial}{\partial x_{i}}\left[\left(\mu+\frac{\mu_{t}}{\sigma_{\varepsilon}}\right) \frac{\partial \varepsilon}{\partial x_{j}}\right]+ \\
& +C_{1 \varepsilon} \frac{\varepsilon}{k}\left(G_{k}+C_{3 \varepsilon} G_{b}\right)-C_{2 \varepsilon} \frac{\varepsilon^{2}}{k}+S_{\eta},
\end{aligned}
$$

where: $C_{1 \varepsilon}, C_{2 \varepsilon}, C_{3 \varepsilon}-$ constans; $\sigma_{k}, \sigma_{\varepsilon}-$ turbulent Prandtl numbers for $k$ and $\varepsilon ; G_{b}$ - the generation of turbulence kinetic energy due to buoyancy; $G_{k}$ - the generation of turbulence kinetic energy due to the mean velocity gradients; $Y_{M}$-contribution of the fluctuating dilatation in compressible turbulence to the overall dissipation rate; $S_{k}$, $S_{\varepsilon}$ - user-defined source terms.

\section{THE GOAF PERMEABILITY}

The coefficient value of gobs permeability is determined based on the value of resistance of rock roof stratification which forms the caving [7]. The resistance of roof rock stratification is its proper loosening resistance acting against the gravity force, that is natural capability of the rock mass to oppose stratification and caving of roof rock to the heading surface (the tensile strength of the forces directed vertically). This resistance determines their tendency to going into caving state.

The resistance of roof rock stratification forming caving is calculated from dependence:

$$
R_{r r s}=\frac{\sum_{i=1}^{n} R_{r r i} \cdot m_{i}}{\sum_{i=1}^{n} m_{i}},
$$

where: $R_{r r s}$ - resistance of roof rock stratification $(\mathrm{Pa})$, $R_{r r i}$ - tensile strength of the rock layers $(\mathrm{Pa}), m_{i}-$ the thickness of layers (m).

This dependence takes into account the influence of the thickness of particular layers of roof rocks on their tendency to going into caving state.

Resistance of roof rock stratification calculated on the basis of Eq. (12), enables to determine permeability coefficient of rockfall goaves from Eq. (13) and (14) from dependence:

$$
k(x)=\frac{\mu_{g}}{r_{0}+a x^{2}},
$$

for $0 \leq x \leq 2 / 3 \cdot l$,

$$
k(x)=\frac{\mu_{g}}{r_{0}+a\left(\frac{4}{3} l-x\right)^{2}},
$$

for $2 / 3 \cdot l \leq x \leq l$.

where: $\mu_{g}$ - the coefficient of dynamic viscosity of air $\left(\mathrm{Nsm}^{-2}\right), l-$ the total length of the longitudinal longwalls (m), $r_{0}, a$ - empirical factor depending on the mininggeological conditions goaf.

Value of empirical coefficient $r_{0}$ and $a$ depends on the resistance of roof rock stratification forming caving.

Value of coefficient $r_{0}$ is determined from Eq. (15):

$r_{0}=\frac{\mu}{k_{0}}$

where: $k_{0}$ - permeability coefficient of rockfall goaves behind the front of the longwall $\left(\mathrm{m}^{2}\right)$.

Value of coefficient $a$ is determined from Eq. (16):

$a=6 \times 10^{9} R_{r r s}^{-1,74}$

Value of permeability coefficient of rockfall goaves behind the front of the longwall is determined on the basis of the dependence:

$k_{0}=\frac{\mu_{g}}{6} \cdot 10^{-10} R_{r r s}^{1,44}$,

Presented dependences were used during determination of permeability coefficient value of gobs in modeling tests.

\section{ANALYSIS OF THE FLOW}

The subject of the analysis was a flow of air stream through the real system of excavations to which methane is emitted from processed body of coal, surrounding layer of roadway and adjacent layer and rockfall goaves in the amount of $15.0 \mathrm{~m}^{3} \mathrm{CH}_{4} / \mathrm{min}$ (Fig. 1).

In such a case, the task of ventilation process, besides providing sufficient amount of oxygen for the operating crew in these excavations, is to prevent exceeding in permissible methane concentration in the mixture with air $(2.0 \%)$, required by the regulations [5].

This aim is achieved by delivery of the stream of fresh air with specified physical and chemical parameters to the excavation. Also very important is determination of zones in rockfall goaves, at which methane concentration could exceed 5\%, that is its lower explosive limit (LEL).

\subsection{Characteristics of Geological-Mining Conditions of the Longwall C-31in Seam 415/1-2}

The longwall C-31in seam $415 / 1-2$ is a longitudinal system with caving roof in the direction from boundary and its mining parameters are equaled:

- length of the longwall $200.0 \mathrm{~m}$

- height of the longwall $573.0 \mathrm{~m}$

- transverse slope $\quad 4^{\circ}$

- longitudinal slope $\quad 8^{\circ}$

The value of the weighted average tensile strength of the rocks on the rocks littering the gob caving this longwall was $3.88 \mathrm{MPa}$.

This longwall was ventilated in "U" system from boundaries. 
In Fig. 1 there is presented the scheme of wall ventilation with indicated line of air distribution.

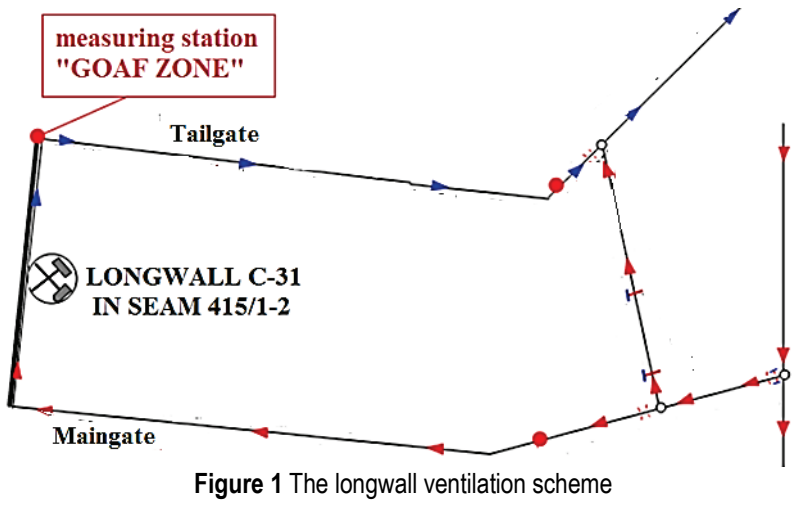

Average of $1299 \mathrm{~m}^{3} / \mathrm{min}$ of air was supplied to the maingate. Release of methane to the exploitation longwall amounted an average of $15.0 \mathrm{~m}^{3} / \mathrm{min}$, and mean value of its concentration at the inlet from the tailgate amounted to $1 \%$.

Modeling tests of the airflow through goaf with caving of this longwall were performed for its length amounted to $372 \mathrm{~m}$

\subsection{The Flow Model}

In order to perform an analysis, there was developed a geometrical model of investigated system of excavations, including main excavations (delivering and removing air from the longwall), longwall and rockfall goaves (rock rubbles resulting from collapse of the roof rocks into space after excavated coal) (Fig. 2).

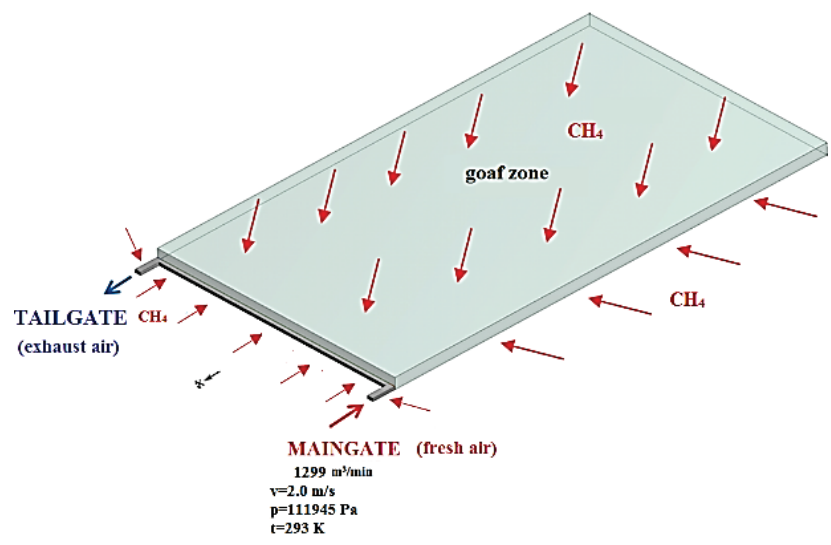

Figure 2 Geometrical model of investigated system of excavations

On the basis of measurement results of physical and chemical parameters of air stream supplied to the wall in real conditions and determined absolute methane content, the boundary conditions of the model were determined.

For analyzed system, it was assumed that length of main excavations equals $20.0 \mathrm{~m}$ and is sufficient for increasing profile of defined velocity at the inlet, whereas length of the longwall is $200.0 \mathrm{~m}$. The height of wall equals $3.0 \mathrm{~m}$, and its width $3.0 \mathrm{~m}\left(S=9.0 \mathrm{~m}^{2}\right)$, whereas main excavations have width of $5.0 \mathrm{~m}$, and height of 3.0 $\mathrm{m}\left(S=15.0 \mathrm{~m}^{2}\right)$.

As an "inlet" boundary condition, a constant velocity field of air stream was assumed. In the inlet cross-section for analyzed excavation there was applied a uniform field distribution in bottom gate with value of $2.0 \mathrm{~m} / \mathrm{s}$ according with results of measurements in real conditions.

For analyzed model, boundary condition for the outflow was defined as an "outlet", while the walls were defined as impermeable, in which surface roughness corresponded to height of $0.2 \mathrm{~m}$, and their temperature (treated as temperature of surrounding rock mass) equaled $305 \mathrm{~K}$. Oxygen concentration in the air stream supplied to the wall according to conducted measurements equaled $20.5 \%$.

It was assumed that rockfall goaves create anisotropic porous medium with different permeability, built of clay slate and sandstone.

Such prepared model was subjected to numerical analysis in order to determine physical and chemical parameters of flowing air stream through analyzed system of excavations and determination of zones where dangerous methane concentration could occur.

\subsection{The Analysis Results}

Based on performed calculations, changes in methane and oxygen concertation along the mining longwall, and also changes in velocity of this mixture flowing through the analyzed system of excavations were determined. Analyses were performed for real velocity of airflow in bottom gate amounting to $2.0 \mathrm{~m} / \mathrm{s}$, and additionally for its two other values $(3.0$ and $4.0 \mathrm{~m} / \mathrm{s})$.

In Fig. 3, determined distributions of velocities of air and methane mixture stream along the longwall are presented.

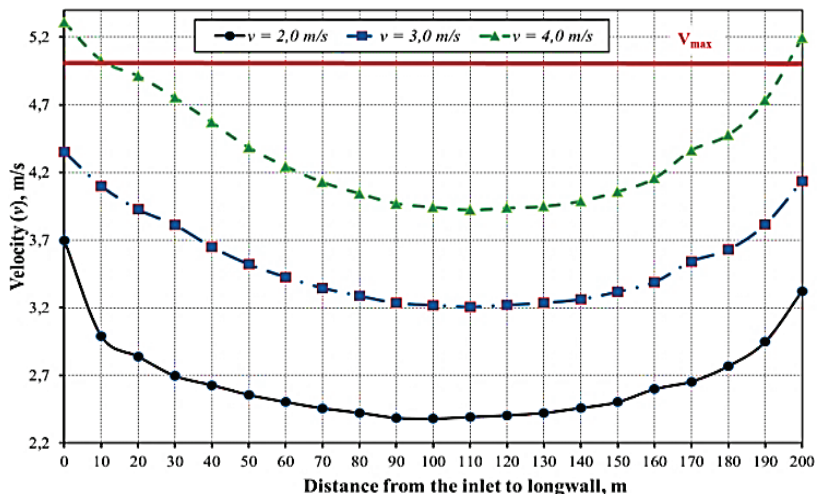

Figure 3 Distributions of velocities of air and methane mixture stream along the longwall

The differences in velocity between the inlet to the bottom gate and the inlet to the mining longwall are the result of different cross sections of these excavations.

Changes in velocity of the air stream on the way of its flow along mining longwall are related to migration of the part of this stream into rockfall goaves and outflows of gases to the wall of the gobs. This causes disturbances in the removal of methane from the longwall, which influence the increase of methane hazard.

The phenomenon of migration of the air stream part from the mining longwall to the rockfall goaves and phenomenon of outflow of the gases from the wall is presented in Fig. 4. 


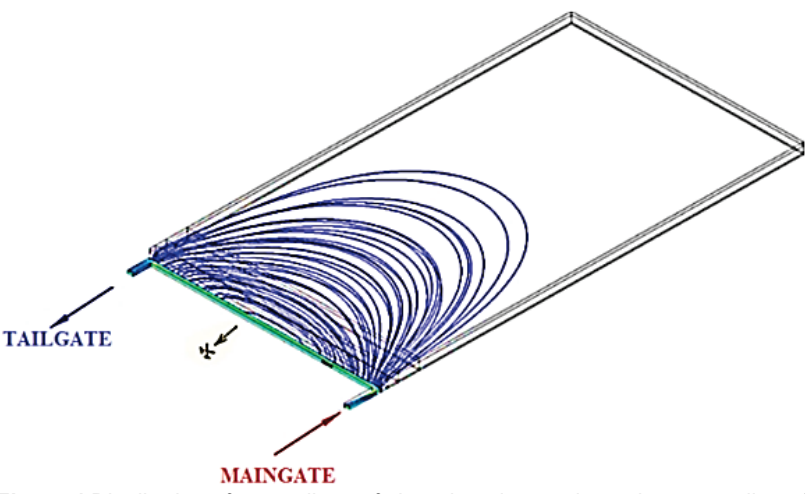

Figure 4 Distribution of streamlines of air and methane mixture in surrounding of mining longwall

In Figs. 4 and 5, there are presented distributions of oxygen and methane concentrations in air stream along longwall for different input air velocities to the bottom gate.

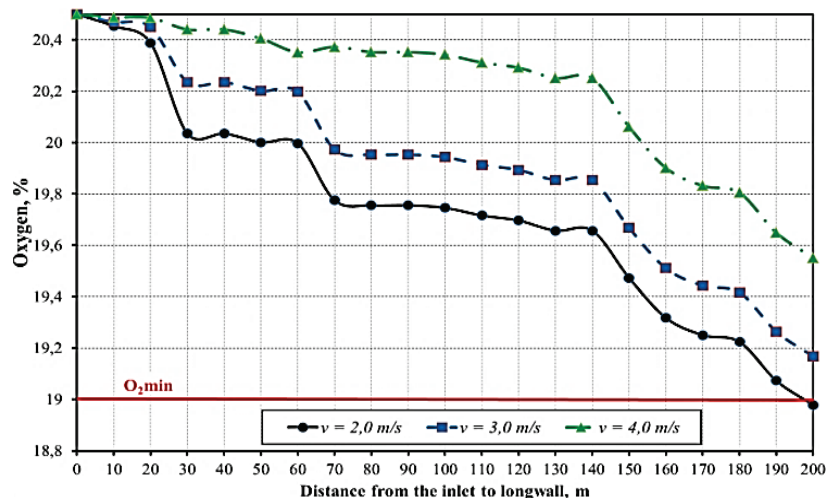

Figure 5 Distributions of oxygen concentrations in air stream along longwall

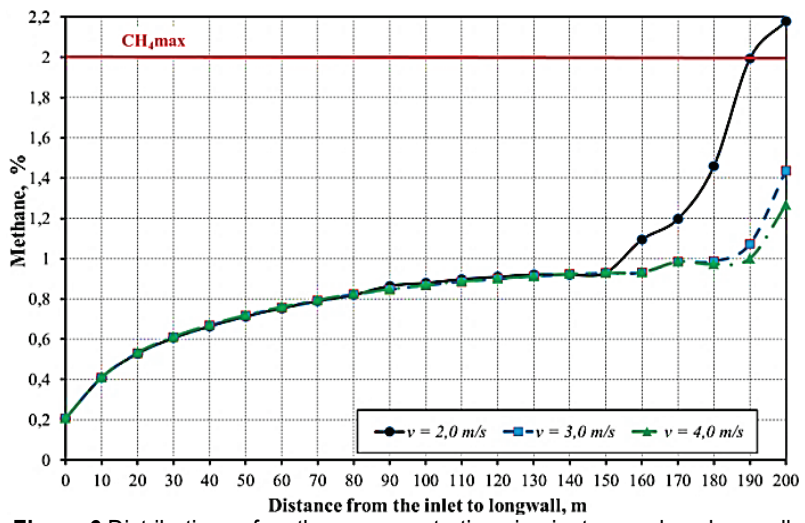

Figure 6 Distributions of methane concentrations in air stream along longwall

Decrease in oxygen concentration in the air stream and methane mixture flowing through the longwall is connected with migration of the part of air stream rich in oxygen to the rockfall goaves and outflow of gases from the rockfall goaves into space of this excavation.

Performed analysis showed that for real conditions permissible methane concentration in the air mixture has been exceeded after $190.0 \mathrm{~m}$ of mining longwall's length. This increase is related to methane emission to the space of excavation resulting from coal mining. If the air stream of higher velocity value was delivered to the longwall, methane concentration would not be exceeded at its whole length.

One should remember that velocity of air stream in longwall must not exceed $5 \mathrm{~m} / \mathrm{s}$.
Results clearly indicate that increase of inlet velocity of the air stream flowing into the main excavation causes faster removal of methane from the longwall and decrease in its concentration.

In Fig. 7 zones of methane concentration exceeding its permissible values in excavations, where mining crew works, are presented, and in Fig. 8 zones with explosive concentration of this gas in rockfall goaves are presented (for $v=2 \mathrm{~m} / \mathrm{s}$ ).

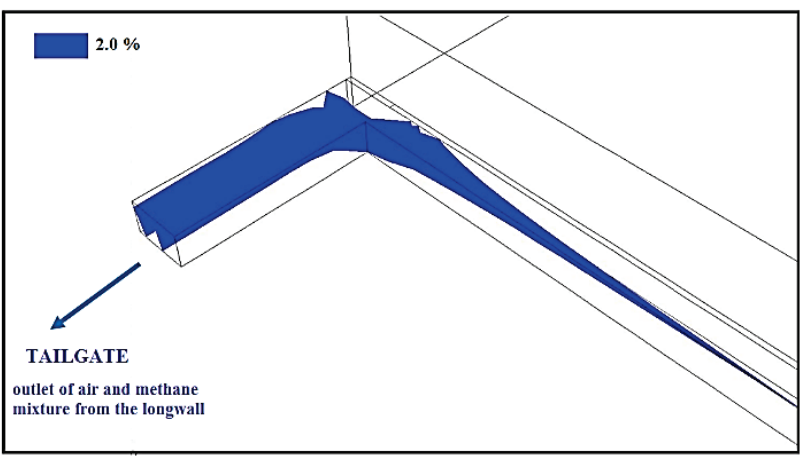

Figure 7 Zones of methane concentration exceeding its permissible values in excavations ( $2 \%$ for $v=2 \mathrm{~m} / \mathrm{s}$ )

Based on the obtained results, one can conclude that the zone of explosive concentration of methane in the rockfall goaves reaches $186.0 \mathrm{~m}$ from the face (for $v=2$ $\mathrm{m} / \mathrm{s}$ ). Together with increase in air velocity, this zone is relocated to the goaves what improves operation safety in this environment.

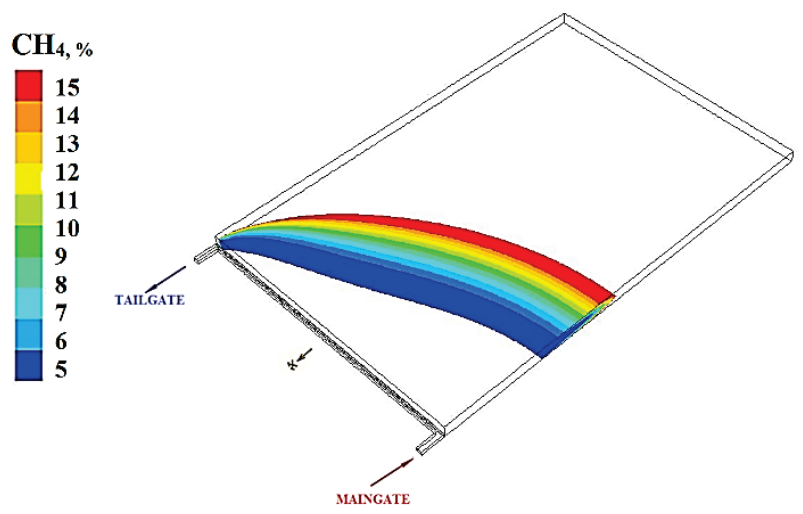

Figure 8 Zones with explosive concentration of this gas in rockfall goaves (for $v=2 \mathrm{~m} / \mathrm{s}$ )

\section{CONCLUSIONS}

Methane emitted during the mining exploitation is dangerous gas both for underground environment and for external atmosphere. In mine excavations after exceeding of permissible concentration, methane becomes an explosive gas, creating a huge hazard for mining crew and the whole underground environment.

Therefore, works in order to prevent such a state, have very significant meaning. To such works one can include research in order to determine distribution of methane concentration in mine excavations and to define factors influencing this distribution.

Tests carried out clearly indicate that numerical methods can be used with success to analyze processes 
related to the ventilation of underground excavations, and also in analyses of their states of emergency.

Obtained results indicate that increasing velocity of airflow through the excavations influences the decrease in methane concentration, which apparently improves work safety in this environment.

Due to the dynamics of phenomena connected with explosion and combustion of methane with huge material losses and victims, in this paper one focused on the state analysis of methane hazard in underground mine excavations.

However, it should be noted that emission of methane from mining excavation to the atmosphere causes its pollution and intensifies greenhouse effect. Additionally, in a case of inflammation or explosion of methane, products of these processes are released to the atmosphere in a form of harmful and poisonous gases.

It is therefore reasonable to say, that investigations of methane hazard in underground working environment are necessary, and their results should be used for prophylactic activities in order to counteract the losses and degradation of natural environment.

\section{REFERENCES}

[1] Ansys Fluent Theory Guide 14.0, 2011.

[2] Elsner, J. W. (1987). Turbulence flow. PWN, Warszawa.

[3] Kabiesz, J. (2014). Annual report on the state of the basic natural hazards and technical coal mining. Katowice. GIG.

[4] Law on Environmental Protection (Dz.U. $2001 \mathrm{Nr} 62$ poz. 627 r.).

[5] Regulation of the Minister of Economy on health and safety, traffic management and specialized fire protection in underground mines górniczych (Dz. U. Nr 139 poz. 1169 z dnia 28 czerwca 2002 r.)

[6] Reddy, A. C. (2012). Development of a Coal Reserve GIS Model and Estimation of the Recoverability and Extraction Costs. Master of Science Thesis, Department of Mining Engineering, West Virginia University.

[7] Szlązak J. (2012). Metody obliczania rozplywu powietrza $i$ rozktadu stężenia metanu $w$ zrobach ścian zawałowych. Przykłady wykorzystania. Wydawnictwo Politechniki Śląskiej, Gliwice.

[8] Szuflicki, M., Malon, A. \& Tymiński, M. (2015). Balance of mineral deposits in Poland at 31.12.2014. Warszawa. Polish Geological Institute - National Research Institute.

[9] Veersteg, K. K. \& Malalasekera, W. (2007). An Introduction to Computational Fluid Dynamics. The Finite Volumne Method. Pearson Education.

[10] Branny, M. (2006). Computer Simulation of flow of air and methane mixture in the longwall-return crossing zone. Archives of Mining Sciences, 51(1), 133-145.

[11] Brodny, J. \& Tutak, M. (2015). Numerical analysis of airflow and methane emitted from the mine face in a blind dog heading. Management Systems in Production Engineering, 18(2), 110-118, https://doi.org/10.12914/MSPE-11-02-2015

[12] Klimanek A. (2013) Numerical modelling of natural draft wet-cooling towers. Archives Computers Methods Engineering, 20(1), 61-109. https://doi.org/10.1007/s11831-013-9081-9

[13] Kurnia, J. C., Sasmito, A. P. \& Mujumdar, A. S. (2014). CFD simulation of methane dispersion and innovative methane management in underground mining faces. Applied Mathematical Modelling, 38, 3467-3484 https://doi.org/10.1016/j.apm.2013.11.067
[14] Kurnia, J. C., Sasmito, A. P. \& Mujumdar, A. S. (2014). Simulation of a novel intermittent ventilation system for underground mines. Tunnelling and Underground Space Technology, 42, 206-215. https://doi.org/10.1016/j.tust.2014.03.009

[15] Milisavljević, V., Tošić, D., Čokorilo, V. \& Ristović, I. (2016). Modelling of at rockbolts parameters for "soko" underground coal mine. Tehnički vjesnik, 23(3), 661-666. DOI: 10.17559/TV-201408251326.

[16] Kurnia, J. C., Sasmito, A. P. \& Mujumdar, A. S. (2012). Computational study of thermal management in underground coal mines: effect of operating ventilation parameters. Singapore. National University of Singapore.

\section{Contact information:}

\section{Jarosław BRODNY, Associate Professor}

Silesian University of Technology

Faculty of Organization and Management,

Str. Roosevelta 26-28, 41-800 Zabrze, Poland

E-mail: jaroslaw.brodny@polsl.pl

\section{Magdalena TUTAK, PhD. Eng}

Silesian University of Technology,

Faculty of Mining and Geology,

Str. Akademicka 2, 44-100 Gliwice, Poland

E-mail: magdalena.tutak@polsl.pl 